\title{
PROPRIEDADE FAMILIAR - EVOLUÇÃO CONCEITUAL E O RECONHECIMENTO FORMAL DE UMA NOVA CATEGORIA RURAL
}

Milton Inácio Heinen*

\begin{abstract}
Resumo
O presente estudo tem como enfoque central a propriedade familiar e sua evolução conceitual, desde o Estatuto da Terra (Lei $n^{\circ}$ 4.504/1964), buscando verificar a influência da Constituição Federal nesta evolução e os seus contornos atuais, resultando na identificação de um público rural específico, com interesses específicos, para o qual, nos termos da Lei $n^{a}$ $11.326 / 2006$, são fixadas diretrizes para a formulação de politicas públicas específicas relacionadas com a obtenção de crédito, assistência técnica e comercialização da produção, a qual é voltada, sobretudo, para o abastecimento local e regional, interferindo positivamente no desenvolvimento rural sustentável e na distribuição de renda no campo. Também na área previdenciária, identifica-se este agricultor familiar como segurado especial, desde que labore em regime de economia familiar e detenha, a qualquer título, área de terra de até 04 (quatro) módulos fiscais. No entanto, esta evolução, com o reconhecimento prático de uma nova categoria de agricultor e empreendedor familiar rural, ainda não foi acompanhada das necessárias mudanças na legislação para que este público seja reconhecido formalmente como categoria específica também para fins de organização sindical e cooperativa.
\end{abstract}

Palavras-chave: Propriedade Familiar. Agricultura Familiar. Agricultura Camponesa. Nova Categoria Rural.

\section{Introdução}

A propriedade familiar, pela primeira vez reconhecida em nosso ordenamento jurídico a partir do Estatuto da Terra, inobstante a sua histórica desconsideração no que diz respeito ao direcionamento das políticas públicas, tem se mostrado de extrema importância na produção de alimentos, distribuição de renda e desenvolvimento sustentável, além de outros aspectos, entre os quais o cultural, evidenciado por relações de convivência com a comunidade e com a natureza.

* Milton Inácio Heinen é advogado, mestre em Direito Agrário, Professor de Direito Agrário e Direito do Trabalho da Faculdade de Direito da Universidade Federal de Goiás e do Curso de Ciências Jurídicas da Pontifícia Universidade Católica de Goiás. 
Posteriormente, outras denominações foram inseridas no nosso ordenamento jurídico, principalmente a partir da Lei n. 8.629/93, dando regulamentação aos dispositivos constitucionais relativos à política agrária; com a Lei $n^{\circ} 9.393 / 96$, que trata de pequenas glebas rurais para fins de imunidade tributária; e agora, com a Lei n. 11.326/06, fixando diretrizes para a elaboração das políticas públicas específicas voltadas para a agricultura familiar.

Estas mudanças de denominação e, conseqüentemente, de conteúdo, serão objetos de análise no presente trabalho. O que se propõe é refletir acerca da evolução conceitual do que vem a ser a propriedade familiar e o empreendimento rural familiar, verificando as influências da Constituição Federal nesta trajetória e a contribuição do referencial legal na constituição de uma nova categoria no campo, entre outras repercussões.

Não resta dúvida acerca da importância histórica e atual da propriedade familiar no desenvolvimento local e regional, notadamente com enfoque no desenvolvimento sustentável, o que supõe democratização da propriedade da terra, distribuição de renda, qualidade de vida e preservação ambiental, entre outros aspectos, o que demonstra a relevância do presente estudo.

\section{A propriedade familiar no Estatuto da Terra (Lei $\left.n^{\circ} 4.504 / 1964\right)$}

Até o advento do Estatuto da Terra (Lei n. 4.504/64) não havia, em nosso ordenamento jurídico, qualquer dispositivo legal específico que fizesse distinção entre imóveis urbanos e rurais e nem mesmo tratando da classificação destes últimos.

O Código Civil de 1916 era, até então, a referência legislativa a respeito da propriedade imóvel, sendo que os dispositivos do Código atual (Lei $\left.\mathrm{n}^{\circ} 10.406 / 02\right)$ diferem pouco da redação daquela época no tocante à propriedade imóvel urbana e rural. 
Contudo, a Constituição Federal de 1946, em seu artigo 156, parágrafo terceiro, já fazia referência á aquisição de área de terra de até 25 hectares através da usucapião agrária, para quem, não sendo proprietário rural nem urbano, comprovasse posse por 10 anos e tornando a área produtiva por seu trabalho e tendo ali a sua moradia. Como se pode verificar, trata-se, apenas com prazos e dimensões diferentes, da usucapião agrária atualmente prevista no artigo 191 da Constituição Federal. Sem a denominação expressa, a Constituição Federal de 1946 mencionou um tipo de propriedade familiar adquirida através da posse/trabalho e a consequente usucapião.

Em 1964, com o reconhecimento da autonomia (legislativa) do Direito Agrário, através da Emenda Constitucional n ${ }^{\circ} 10$, de 09 de novembro daquele ano, e na sequência, com a promulgação do Estatuto da Terra (Lei $\left.n^{\circ} 4.504 / 64\right)$, por vezes chamado de Código Agrário Brasileiro, passamos a contar com regras, conceitos e institutos específicos atinentes às relações jurídicas agrárias, restando à legislação civil, a partir dali, apenas a aplicação subsidiária.

A Lei $\mathrm{n}^{\circ} 4.504 / 64$, pela primeira vez detalhando os elementos que compõem o conceito de função social da terra, utilizou um dimensionamento de referência regional, a depender das condições de produção e obtenção de resultados satisfatórios, para estabelecer tipos distintos de imóveis rurais, tanto em relação ao tamanho destes, como levando em conta os níveis e condições de utilização ou exploração dos mesmos.

Para tanto, a referência utilizada foi a propriedade familiar. Conforme previsto no artigo $4^{\circ}$, III do Estatuto da Terra, a classificação dos imóveis rurais seria feita tendo por base o módulo rural. No entanto, ao definir o que seja módulo rural, o legislador remeteu ao inciso anterior (inciso II do referido artigo), o qual definiu a propriedade familiar. Nestas condições o módulo rural ficou fixado na medida da propriedade familiar e esta varia, quanto à dimensão, de uma região para outra, levando-se em conta a localização, qualidade da terra, e demais condições de produção, 
além do tipo de exploração e atividade predominante na região, como se verifica no referido dispositivo legal.

Assim, a propriedade familiar passou a ter a medida do módulo rural e, como dito, juntamente com a forma e níveis de utilização e produtividade, serviu de referência para a classificação dos imóveis rurais em latifúndios, empresas rurais, propriedades familiares e minifúndios.

$\mathrm{O}$ artigo $4^{\circ}$, II do Estatuto da Terra define a propriedade familiar como sendo:

\footnotetext{
"o imóvel rural que, direta e pessoalmente explorado pelo agricultor e sua familia, lhes absorva toda a força de trabalho, garantindo-lhes a subsistência e o progresso social e econômico, com área máxima fixada para cada região e tipo de exploração, e eventualmente, trabalhado com ajuda de terceiros".
}

A partir desta definição, é de se concluir que a propriedade familiar teve sua dimensão limitada a um módulo rural, desde que cumpridas as outras exigências relacionadas com a exploração da área com o trabalho próprio e da família do agricultor. Ultrapassada a medida do módulo e observadas as exigências mínimas de aproveitamento e rendimento econômico, o imóvel rural passou a levar a denominação de empresa rural e, não atingindo os índices mínimos o mesmo imóvel era classificado como latifúndio, ao passo que o imóvel com área inferior a um módulo rural, portanto menor do que a medida fixada para a propriedade familiar, era classificado como minifúndio.

A propriedade familiar era, então, uma medida padrão a viabilizar o uso adequado da terra de modo a alcançar dignidade ao produtor e sua família através da produção necessária à subsistência e, ao mesmo tempo, atendendo aos interesses e necessidades da coletividade através da venda dos excedentes produzidos, o que a lei chama de progresso social e econômico. A partir da definição da propriedade familiar, a área inferior à medida fixada foi denominada de minifúndio, a ser combatido e gradativamente eliminado, juntamente com o latifúndio, por serem 
considerados pelo legislador como sendo nocivos à sociedade, conforme estabelece o Estatuto da Terra, no artigo 16, ao dizer dos objetivos da reforma agrária.

Nos termos da Mensagem 33, que encaminhou ao Congresso Nacional o projeto que resultou no Estatuto da Terra, o que se buscava era implementar o comando constitucional de "promover a justa distribuição da propriedade, com igual oportunidade para todos, condicionando o uso da propriedade ao bem estar social"1. Ao mesmo tempo, o Estatuto buscava colocar em prática o compromisso assumido pelo Brasil na Carta de Punta Del Este (Uruguai/1964), onde, conforme disposto no artigo $6^{\circ}$, as repúblicas americanas procurariam, entre outros objetivos a serem atingidos nesta década:

\begin{abstract}
"impulsionar, respeitando as particularidades de cada país, programas de reforma agrária integral, encaminhada à efetiva transformação onde for necessária a modificação das estruturas dos injustos sistemas de posse e uso da terra, a fim de substituir o regime de latifúndios e minifúndios por um sistema justo de propriedade, de maneira que, complementada por crédito oportuno e adequado, assistência técnica, comercialização e distribuição dos seus produtos, a terra se constitua para o homem que a trabalha, em base da sua estabilidade econômica, fundamento do seu crescente bem estar e garantia de sua liberdade e dignidade" (MIGUEL NETO: 1997, p. 38).
\end{abstract}

Não se tratava de adotar a propriedade familiar como sendo a única a ser preservada ou incentivada, mas esta foi colocada como referência para a política de acesso à terra e, com as políticas públicas de apoio, meio de alcance da dignidade.

Independente do fato do Estatuto da Terra ter sido promulgado, inclusive às pressas, sob a influência das pressões internacionais, sobretudo norte americanas, os seus dispositivos permitiam uma ação e intervenção mais ampla do Estado na estrutura fundiária brasileira do que os dispositivos legais atuais. 


\section{A Constituição Federal de 1988 abrindo caminho para a ampliação do conceito de propriedade familiar}

A Constituição Federal de 1988 nos traz um referencial geral para todo ordenamento jurídico. Trata-se da dignidade da pessoa humana, fundamento da república (art. $1^{\circ}$, III da $\mathrm{CF}$ ), com caráter de princípio superior, ao qual todos os demais princípios e regras jurídicas devem se subordinar.

Em consonância com esta orientação maior, a Constituição Federal, no art. $5^{\circ}$, XXVI, portanto entre os direitos e garantias fundamentais, traz uma proteção especial à pequena propriedade, mesmo que a definição desta tenha ficado para a legislação ordinária. Contudo, não ocorreu garantia especial a toda e qualquer pequena propriedade, mas apenas aquela trabalhada pelo agricultor e sua família.

O referido inciso dispõe que:

“ XXVI - a pequena propriedade rural, assim definida em lei, desde que trabalhada pela família, não será objeto de penhora para pagamento de débitos decorrentes da sua atividade produtiva, dispondo a lei sobre os meios de financiar o seu desenvolvimento".

Como se vê, a $\mathrm{CF} / 88$ não faz referência expressa à propriedade familiar e também não apresenta uma nova definição desta. No entanto, a proteção especial estabelecida neste inciso como garantia fundamental faz referência a um tipo especial de pequena propriedade, qual seja aquela trabalhada pelo agricultor e sua família. Assim, mesmo não trazendo esta denominação, referiu-se claramente à pequena propriedade rural que possui um caráter de propriedade familiar.

Cabe lembrar que a proteção constitucional especial dada à pequena propriedade rural trabalhada pelo agricultor já havia ocorrido em 1961, quando a Constituição Federal de 1946 foi emendada (E.C. $n^{\circ}$ 5), acrescentando-se parágrafo único ao artigo 29, nestes termos: "Parágrafo único - O imposto territorial rural não incidirá sobre sítios de área não 
excedente a vinte hectares, quando os cultive, só ou com sua família, o proprietário" 2 .

De qualquer forma, faltava a definição de pequena propriedade rural, e igualmente da média propriedade rural, nomenclatura nova inserida no texto constitucional, como ficou determinado no artigo $5^{\circ}$, XXVI e no artigo 185, I, ambos da Constituição Federal.

\section{A nova classificação das propriedades rurais dada pela Lei $\mathbf{n}^{\circ}$ $8.629 / 93$}

As novas denominações das propriedades rurais, inseridas no texto constitucional, foram objeto de definição na Lei $n^{\circ}$ 8.629/93, assim dispondo no seu inciso $4^{\circ}$ inciso II: - Pequena Propriedade - o imóvel rural: a) de área compreendida entre 1 (um) e 4 (quatro) módulos fiscais. b) (vetado). c) (vetado).

É oportuno lembrar que o módulo fiscal, criado em 1979, pela Lei $\mathrm{n}^{\circ}$ 6.746, sendo um por município, tinha então a finalidade de servir como referência para a fixação das alíquotas de incidência e apuração do Imposto Territorial Rural, sendo que a partir do Decreto $\mathrm{n}^{\circ}$ 84.685, de 1980 (artigo 22), passou a ser utilizado na classificação dos imóveis rurais, o que foi confirmado pela Lei $\mathrm{n}^{\circ} 8.629 / 93$, como se vê nas definições acima citadas.

As letras "b" e "c" do dispositivo acima citado, vetadas na ocasião da promulgação da Lei $n^{\circ}$ 8.629/93, já faziam referência clara à pequena propriedade como sendo a propriedade familiar, assim dispondo:

(b) explorado direta e pessoalmente pelo agricultor e sua família, admitida a ajuda eventual de terceiros,nas épocas de pico de demanda de mão-de-obra; c) que garanta a absorção de toda a mão-de-obra ativa do conjunto familiar, assegurando, ainda, a sua subsistência e o progresso social e econômico"3.

Percebe-se aí que os dispositivos vetados faziam referência clara à pequena propriedade como sendo propriedade familiar. No entanto, as razões dos vetos referem-se a problemas resultantes da identificação da 
propriedade de pequena dimensão de titularidade de pessoas jurídicas, restando dúvidas sobre qual denominação lhes seria dada. Portanto, o veto poderia ter sido evitado se o legislador tivesse identificado a propriedade familiar com seus componentes específicos,além da mera dimensão da pequena propriedade, como sendo aquela que possui entre 1 e 4 módulos fiscais de terra.

A partir da Lei $\mathrm{n}^{\circ} 8.629 / 93$, o cadastro nacional de imóveis rurais passou a utilizar as denominações de minifúndio (para imóveis rurais com área menor que um módulo fiscal), pequena propriedade (entre 1 e 4 módulos fiscais), média propriedade (imóvel com área acima de 4 e até 15 módulos fiscais) e, por exclusão, a grande propriedade, como sendo aquela com área acima de 15 módulos fiscais, sendo que qualquer uma delas, como complemento cadastral poderá levar a designação de propriedade produtiva ou improdutiva, a depender do grau de utilização da terra e da eficiência na exploração. Desta forma, as denominações latifúndio, empresa rural e propriedade familiar deixaram de constar no cadastro nacional de imóveis rurais como tipos específicos de propriedade imóvel rural, mantendo-se, todavia, a denominação de propriedade familiar para a incidência de políticas públicas específicas.

\section{A criação do PRONAF ampliando o conceito de agricultura familiar}

A impenhorabilidade da pequena propriedade rural, desde que trabalhada pela família, inserida no texto constitucional entre os direitos e garantias fundamentais, de extrema importância na proteção da propriedade familiar, contraditoriamente, se constituiu num problema nos primeiros anos de vigência da Carta Magna. Não sendo objeto de penhora, também não seria utilizada como garantia em face das dividas contraídas pelo agricultor, em especial nos financiamentos de investimento e custeio das atividades produtivas rurais. Nestas condições, fecharam-se as portas ao crédito rural para os agricultores familiares, uma vez que os agentes financeiros não se 
contentavam apenas com a garantia pignoratícia, tendo como objeto apenas a produção, máquinas e animais do agricultor.

Cabe observar que a Lei $\mathrm{n}^{\circ} 8.171 / 1991$, tratando da política agrícola, em seu artigo $3^{\circ}$, inciso $\mathrm{X}$, já inseriu entre os objetivos desta o apoio institucional ao produtor rural, com prioridade de atendimento ao pequeno produtor e sua família. Aqui, mesmo sem tornar explícito, o legislador deu a entender que se dará prioridade ao agricultor familiar, ou seja, aquele que labora nas condições fixadas para a propriedade familiar. No artigo 12 da mesma lei, o legislador, no que tange à pesquisa agrícola, fixa a prioridade no desenvolvimento de tecnologias adaptadas aos pequenos agricultores, enfatizando a produção de alimentos básicos e, desta forma, dá preferência à agricultura familiar. Igualmente, no artigo 17, a referida lei faz referência aos pequenos produtores, garantindo-lhes atendimento gratuito em termos de assistência técnica, além de estimular a organização da população rural, respeitando a organização da unidade familiar.

A garantia constitucional e o tratamento diferenciado e preferencial fixado pela lei regulamentadora da política agrícola levaram as organizações representativas dos agricultores familiares a reivindicarem, entre outras políticas públicas, linhas de crédito e condições especiais de financiamento para viabilizar as atividades de produção, buscando a aplicação prática do disposto na Lei $\mathrm{n}^{\circ}$ 8.171/91. Assim, em 1996 é publicado o Decreto $\mathrm{n}^{\circ}$ 1.946, que cria o PRONAF - Programa Nacional de Fortalecimento da Agricultura Familiar, dispondo sobre seus objetivos e ações a serem desenvolvidas de forma descentralizada, com o envolvimento dos estados e municipios 4 .

Fruto do árduo trabalho de mobilização e convencimento das organizações representativas deste novo segmento de produtores rurais, o publico beneficiário do PRONAF foi melhor definido no Decreto $n^{\circ} 3.991$, de 2001, estabelecendo, no artigo $5^{\circ}$, entre outros requisitos, que são considerados agricultores familiares aqueles que possuírem a qualquer título área de terras não superior a 4 (quatro) módulos fiscais. 5 
Nestas condições, visando definir os beneficiários de linhas especiais de crédito rural, entre outras políticas públicas, como a preferência na assistência técnica e apoio na comercialização da produção, o PRONAF acaba por identificar o limite máximo de área de terra a se enquadrar como propriedade familiar com aquele fixado na classificação dos imóveis rurais como pequena propriedade rural, pela Lei no 8.629/93.

Não há perfeita identidade entre pequena propriedade rural e propriedade familiar, na medida em que nem toda pequena propriedade é considerada propriedade familiar, uma vez que esta possui outros requisitos, entre os quais a renda familiar a ser obtida predominantemente pelo trabalho do grupo familiar e a administração pessoal do empreendimento. Igualmente, a terra menor que um módulo fiscal, explorada pelo agricultor e sua família também se identifica com a propriedade familiar, desde que cumpridos os demais requisitos, ao passo que na classificação dos imóveis rurais nos cadastros do INCRA - Instituto Nacional de Colonização e Reforma Agrária, aparecerá com a denominação de minifúndio.

\section{A Lei $n^{\circ} 11.326 / 06$ - Consolidação do conceito de propriedade e empreendimento rural familiar}

Como dito anteriormente, a Constituição Federal, ao dar proteção especial à pequena propriedade rural, desde que trabalhada pela família, efetivamente se referiu à propriedade familiar que, a partir da definição legal de pequena propriedade, abriu caminho para a ampliação do conceito de propriedade familiar.

As normas reguladoras do PRONAF contribuíram no mesmo sentido, a partir da fixação de um público alvo denominado de agricultor familiar o qual, entre outras exigências, possui área de terra limitada a 4 
(quatro) módulos fiscais. Contudo, tratando-se de regulação apenas em decretos, os organismos representativos deste segmento rural tiveram atuação fundamental para a consolidação dos novos contornos da agricultura familiar através de lei específica.

Neste contexto é promulgada a Lei $\mathrm{n}^{\circ} 11.326 / 06$, que fixa diretrizes específicas para a formulação da política nacional da agricultura familiar e empreendimentos familiares rurais.

A utilização de terminologia diferente daquela estabelecida no Estatuto da Terra poderia levar à indagação acerca da substituição, ou não, da expressão e conteúdo da propriedade familiar pelas novas denominações de agricultor familiar e empreendedor familiar rural.

Como bem lembrado por Benedito Ferreira Marques, com o veto às alíneas "b" e "c" daquele dispositivo, a pequena propriedade ficou definida apenas em função do tamanho da área, sem levar em conta o titular e a forma de exploração (MARQUES: 2012, p. 59). Evidentemente o veto presidencial foi justificável para evitar que a única propriedade reconhecida como pequena, além da dimensão, seria aquela trabalhada pelo agricultor e sua família, ao passo que há, de fato, pequenas propriedades não consideradas como propriedade familiar. Daí a necessidade de lei específica fixando os requisitos para que a pequena propriedade seja consideradas propriedade familiar e, igualmente, para identificar o que vem a ser empreendimento rural familiar, independente da titularidade da propriedade, de forma que o parceiro outorgado e o arrendatário, além de eventuais outras formas de posse e uso da terra, e a depender do limite de área explorada mediante contrato de uso temporário da terra, combinado com as demais exigências da lei específica, também pode ser identificados como empreendedores rurais familiares.

A Lei $\mathrm{n}^{\circ} 8.629 / 93$, no artigo 19, referindo-se aos beneficiários da reforma agrária, inclui os agricultores cujas propriedades não alcancem a dimensão da propriedade familiar (inciso V ), o que, em outras palavras, seriam os proprietários de minifúndios. De qualquer forma, esta regra 


\section{MILTON INÁCIO HEINEN}

anterior à Lei $\mathrm{n}^{\circ}$ 11.326/06 não está relacionada com a ampliação do conceito de propriedade familiar fixada nesta última. Por outro lado, esta lei fixadora das diretrizes para a formulação de políticas voltadas para a agricultura familiar não exclui a área de terra inferior a um módulo fiscal da condição de propriedade familiar, desde que cumpra as demais exigências legais para obter esta designação.

Cabe, portanto, concluir que a propriedade familiar só não passou a compreender a área de terra de um a quatro módulos fiscais, e não chegou a coincidir com o conceito de pequena propriedade, em razão do veto aos dispositivos que tratavam da forma de sua exploração.

Contudo, percebe-se que, a partir do disposto na Lei n. 11.326/06, há uma conjugação de elementos, envolvendo área de até 04 módulos fiscais e não apenas de 01 a 04 módulos fiscais, exploração da atividade com mão de obra predominante do grupo familiar, administração do empreendimento pelo titular e renda predominantemente oriunda da atividade do empreendimento familiar rural, nos mesmos termos fixados nos dispositivos vetados na Lei n. 8.629/93, quando da definição de pequena propriedade. $\mathrm{Na}$ ocasião, a definição de pequena e de média propriedade rural, regulamentando os dispositivos constitucionais, resultou em classificação específica para fins cadastrais, não levando em conta as condições de exploração dos ditos imóveis. Portanto, o que a Lei n. 8.629/93 não fez em razão dos vetos, foi feito agora com a Lei n. 11.326/06, dando efetiva regulamentação ao comando constitucional de proteção à pequena propriedade rural familiar.

Nestes termos, a definição de propriedade familiar do Estatuto da Terra estaria totalmente superada pela nova legislação? Pela regra estabelecida no artigo $4^{\circ}$, "d" do Decreto $\mathrm{n}^{\circ} 84.685 / 80$, a propriedade familiar é elemento componente da fixação do módulo fiscal. Desta forma, corroborado pelo estabelecido no artigo 19, inciso V da Lei n. 8.629/93 a definição do Estatuto da Terra ainda mantém uso prático, ao menos como 
medida delimitadora do limite mínimo de área do imóvel que não será denominado de minifúndio.

Contudo, esta denominação de minifúndio tem aplicação prática específica nos cadastros de imóveis rurais com área inferior a um módulo fiscal, portanto, menor do que a pequena propriedade. Assim, é possivel concluir que a propriedade familiar, a partir do alcance que lhe é dada pela Lei n. 11.326/06, não possui um limite mínimo, qual seja o de um módulo fiscal, de modo que também a área de terra classificada como minifúndio, desde que trabalhada nas condições previstas na referida lei, identifica-se com a propriedade familiar. No outro extremo, referida lei fixa um limite máximo de 04 (quatro) módulos fiscais para a propriedade e empreendimento familiar rural. Portanto, não há limite mínimo de área de terra para que o empreendimento rural seja considerado familiar e, nestas condições, beneficiário de políticas públicas específicas.

Como demonstrado, a Lei $\mathrm{n}^{\circ} 11.326 / 06$ apresenta uma identidade geral de elementos a integrarem a noção de agricultor familiar fixados nas normas que regulam o Programa Nacional de Fortalecimento da Agricultura Familiar - PRONAF. As condições para a obtenção do crédito ou o benefício das politicas específicas são as mesmas agora relacionadas na lei de diretrizes para a formulação da Política Nacional da Agricultura Familiar.

Também quanto à garantia constitucional de impenhorabilidade da pequena propriedade, não há diferença de tratamento, uma vez que a definição desta é de área de até 04 módulos, desde que trabalha pela família.

Infelizmente o legislador não adotou o mesmo critério para fins de imunidade e isenção tributária, sem uma justificativa plausível para tanto. A Constituição Federal, no artigo 153, fez referência a pequenas glebas e estas foram definidas de modo diverso conforme a região, nos termos do disposto na Lei $n^{\circ} 9.393 / 96$. O artigo $2^{\circ}$ da referida lei fixa, com critérios regionais, o que vem a ser pequena gleba, cuja imunidade tributária também está condicionada à exploração pelo agricultor e/ou sua família, de modo a não seguir o critério de propriedade e empreendimento rural familiar. 
Levando em conta os objetivos da política agrícola, de apoio prioritário à agricultura familiar e, por outro lado, a importância econômica, social e ambiental que esta tem para a sociedade, os empreendimentos familiares de até 04 módulos fiscais, cumpridas as demais exigências da condição de agricultura familiar fixadas na lei, deveriam ficar isentas do ITR.

\section{Outras repercussões da definição de agricultor familiar e empreendimento rural familiar}

6.1. A usucapião constitucional agrária nos mesmos limites da pequena propriedade rural familiar

A ideia de propriedade familiar ou empreendimento familiar rural não está necessária e exclusivamente vinculada ao domínio da terra. Isto significa dizer que a posse de área de terra com a observância dos elementos da propriedade familiar leva ao mesmo conceito, até porque, atendidas as exigências legais, é reconhecido o domínio da área por sentença na ação de usucapião. Neste sentido, o legislador não foi feliz ao fixar um único limite, em âmbito nacional, capaz de resultar na aquisição da propriedade pela usucapião constitucional. Em vez de estabelecer o limite geral de 50 hectares, que em determinadas regiões se traduz na aquisição de minifúndio, teria sido melhor fazer referência à pequena propriedade, desde que trabalhada pela família, o que, pelas regras atuais, é claramente a propriedade familiar. Neste sentido, foi mais feliz o legislador quando da discussão, aprovação e promulgação do Estatuto da Terra, ao inserir em seu artigo 98, a possibilidade de aquisição, pela usucapião, de área até o limite do módulo, evitando assim a aquisição de minifúndios.

Além disso, o direito de exploração é concedido por outras formas, além da titulação, como é o caso da concessão de uso real, alternativa prevista pela Constituição Federal (art. 189) como instrumento para 
distribuição de terras em projetos de reforma agrária, como bem lembrado por Benedito Ferreira Marques (MARQUES, 2012, p. 73).

\subsection{O agricultor familiar como segurado especial do RGPS}

As Leis $\mathrm{n}^{\circ} 5.889 / 73,8.212 / 91$ e $8.213 / 91$, sofreram alterações pela Lei $\mathrm{n}^{\circ} 11.718$, ampliando a abrangência dos segurados especiais. No artigo 14-A da lei do trabalho rural foi acrescida regra de contratação de trabalhadores para serviços de curta duração, simplificando esta possibilidade para o produtor rural pessoa física, desde que devidamente autorizado por negociação coletiva realizada com o sindicato da categoria profissional. Esta alteração, por sua vez, trouxe reflexos na legislação previdenciária acima citada. As alterações efetuadas permitem que o produtor rural que labora em regime de economia familiar, em área de até 4 módulos fiscais contrate mão de obra assalariada por até 120 dias ano sem que perca a condição de segurado especial.

Como visto, o enquadramento previdenciário segue o mesmo limite máximo fixado pela legislação para pequena propriedade, desde que trabalhada pelo agricultor e sua família, ou seja, dentro dos mesmos critérios da propriedade rural familiar.

O que muda é o fato que este agricultor familiar pode contar com ajuda temporária de mão de obra assalariada, limitadas a 120 dias de serviço por ano, sem perder a condição de segurado especial. Do ponto de vista trabalhista e da sua relação com os meios de produção, não resta dúvida que se identifica como empregador, ao menos parcialmente, e ao mesmo tempo mantém a condição de agricultor familiar uma vez que, na maior parte do ano, apenas envolve a força de trabalho do grupo familiar. Esta realidade reforça a identificação de um novo segmento ou categoria rural que é, ao mesmo tempo, econômico e profissional.

\subsection{Agricultura familiar e Agricultura camponesa}


Tendo em vista as distinções feitas principalmente no campo da antropologia e da sociologia, em relação à propriedade familiar e o titular da exploração, designado como agricultor familiar, em comparação com a designação de agricultura camponesa. Estas designações também levam em conta o nível de integração à economia competitiva do tipo capitalista, ou não, assim como a capacidade de obtenção de renda e produção de excedentes, ou então, a limitação do resultado a mera subsistência do agricultor. David Caume, utilizando-se de dados coletados em diversos municípios do Estado de Goiás, afirma que "a produção familiar na agricultura apresenta-se, contemporaneamente, com uma diversidade de características" (CAUME, 1997, p. 17), fazendo referência à integração, ou não, do dito agricultor à economia de mercado. Conforme referido autor, propriedade e trabalho estão intimamente ligados à família. Verifica-se uma unidade de produção específica, com o controle da família sobre os meios de produção, envolvendo a terra, mão de obra e instrumentos, além da responsabilidade pela efetivação do processo de trabalho.

No entanto, há enfoques distintos da atividade exercida pelo agricultor e sua família, com a agregação de outros aspectos de análise. Daí surgem as diferenças em relação à agricultura familiar e a agricultura camponesa, apesar de ambas possuírem como base a propriedade do tipo familiar, cujos limites máximos estão fixados na legislação, como já se verificou.

Assim, a designação de agricultura camponesa, além do aspecto econômico da exploração, resulta da verificação de existência de outros fatores, identificando-a como um modo de fazer agricultura e de viver das familias, englobando o modo de apropriação, redistribuição e consumo dos bens materiais e sociais, envolvendo os saberes e experiências de produção vivenciados pela comunidade, intercâmbio de informações, diversificação de cultivos, solidariedade comunitária, além da relação afetiva com a terra, plantas e animais, entre outros aspectos, entre os quais a preocupação com 
a matriz tecnológica capaz de garantir a preservação ambiental (CAUME, 1997, p. 26 e 27).

Nestas condições, no entender de Horácio Martins de Carvalho e Francisco de Assis Costa (cfe. CALDART et alli: 2012, p. 29), o modo camponês de fazer agricultura se contrapõe ao modo capitalista dominante, apresentando-se na formação social brasileira, com uma lógica própria de produzir e de viver na terra. Isto, no entanto, não significa que o camponês não busca e não obtém renda, ou que sua atividade fica restrita à mera subsistência da família. Ao contrário, o camponês busca renda com o crescimento do máximo valor agregado, mantendo a sua autonomia no processo produtivo e de venda da produção, seja individualmente ou através de organizações próprias, rejeitando assim a crescente subordinação à forma capitalista de produção e integração, intensificada sobretudo a partir da década de 1980 com a crescente artificialização do processo de produção na agricultura.

Assim, a denominação de agricultura familiar abrange a atividade integrada e subordinada aos comandos e interesses da indústria, via contratos de produção e integração, além da produção também para a subsistência, ao passo que a agricultura camponesa, incorporando os elementos da atividade agrícola familiar, com um modo de vida diferenciado, de convivência com a terra, animais, plantas e comunidade, busca manter sua autonomia, sem abrir mão da modernidade e da adoção de novas técnicas de cultivo e agregação de valor, sempre pautada pela preservação do ambiente e dos valores culturais e comunitários que lhe são próprios.

No entender de Carvalho e Costa, há uma tensão econômica, social, política e ideológica gerada no confronto entre a lógica camponesa e a capitalista de se fazer agricultura que acompanha a nossa história desde o Brasil colonial, todavia não se restringindo ao aspecto da produção, envolvendo, ainda, "concepções e práticas de vida familiar, produtiva, social, cultural e de relação com a natureza que, não obstante coexistirem numa 
mesma formação social, negam-se mutuamente, são antagônicas entre si." (cfe. CALDART et alli: 2012, p. 31).

De qualquer forma, e possivelmente buscando negar ou abafar uma conotação mais política e ideológica de agricultura, de combate ao modelo capitalista, monocultor e predominante predador, consagrou-se formalmente na lei, a partir de 2006, a expressão Agricultura Familiar, delimitando o público beneficiário de políticas públicas específicas.

\subsection{Um novo enquadramento sindical rural}

Nas condições até aqui expostas, o agricultor familiar não se identifica com os interesses dos empregados rurais e demais trabalhadores rurais autônomos, ao passo que também não é plenamente empregador. Identificar-se aí uma nova categoria no campo.

A propriedade familiar e, no mesmo enfoque, a agricultura familiar tem um outro aspecto que realça a sua importância. Trata-se do aspecto cultural, da convivência, da mútua ajuda e socorro nas necessidades, das iniciativas de troca de produtos e serviços, os métodos de trabalho, demonstrando a existência de uma cultura camponesa de alto significado para a sociedade, como dito anteriormente, além da sua importância estratégica na produção de alimentos, no abastecimento local e regional, com a consequente distribuição de renda. No entanto, o modelo predominante de produção, denominado de agronegócio, vem destruindo os laços acima citados, fazendo da terra mero substrato para dali retirar resultados que deem lucro, não interessando a que preço.

Por estas razões, também não se justifica manter critério diferenciado para o enquadramento sindical diante das novas regras da agricultura familiar fixadas pela Lei n. 11.326/06. Tratando-se de agricultura familiar, com os aspectos acima citados, que a diferenciam do agronegócio, os ocupantes de terra a qualquer título, com área de até 04 módulos fiscais, desde que presentes os demais elementos da atividade 


\section{MILTON INÁCIO HEINEN}

familiar fixados na referida lei, devem, por questão de identidade, ser reconhecidos como categoria específica, capaz, por consequência, de se organizar em sindicato próprio.

Contudo, não é esta a regra em vigor, que por sinal vem sendo combatida e, na prática, superada, por reiteradas decisões do poder judiciário, ao reconhecer o assalariado rural e o agricultor familiar como sendo duas categorias específicas e com interesses e necessidades distintos, a integrarem um mesmo sindicato, mais genérico, denominado de sindicato dos trabalhadores rurais. $O$ fato é que a norma reguladora do enquadramento sindical rural, o Decreto-Lei 1166, de 1971, na sua redação atual com as modificações introduzidas pela Lei n. 9.701/98, fixa como limite de área a se enquadrar na condição de trabalhador rural, o detentor a qualquer título de área de terra de até 2 (dois) módulos rurais, desde que não explore a atividade na condição de empregador.

Percebe-se, então, que a identidade de agricultor familiar, de empreendedor familiar rural ou propriedade familiar, fixada na legislação mais recente, não é respeitada na fixação do enquadramento sindical rural. Estamos, portanto, diante de situação em que se trata do mesmo público com critérios distintos. Além do mais, o público identificado como agricultor familiar, principalmente se agregarmos as concepções que o identificam como camponês, não se sente representado pelo mesmo sindicato que agrega as grandes empresas e empreendimentos rurais identificados com o agronegócio, ao qual a agricultura camponesa se contrapõe.

De fato, parte do público identificado como agricultor familiar e, portanto, defensor dos mesmos interesses e beneficiário das mesmas políticas públicas, nos termos da legislação atual, integra o sindicato rural, ou sindicato dos produtores rurais e a outra parte integra o sindicato dos trabalhadores rurais.

Trata-se, portanto, da identificação de uma categoria especial no campo, com interesses e área de atuação próprios, que deve ser reconhecida enquanto tal, tendo por base os aspectos anteriormente abordados, 
garantindo-lhes na lei direito de organização em sindicato, como categoria específica, o que, aliás, já foi reconhecido reiteradas vezes pelo poder judiciário, identificando a especificidade e garantindo o direito constitucional de livre organização, sem ferir a atual limitação pela imposta unicidade sindical.

\section{Considerações finais}

Nos aspectos abordados neste estudo resultou demonstrado que a Constituição Federal de 1988 propiciou a ampliação do conceito de propriedade familiar e, mais do que isto, em face do tratamento diferenciado na aplicação das políticas públicas (financiamentos, assistência técnica, comercialização da produção, obtenção de beneficios previdenciários, etc), permitiu a identificação e constituição de uma nova categoria específica rural. Esta já é reconhecida, na prática, no âmbito sindical e na organização em cooperativas, apesar dos limites ou impeditivos legais ainda existentes.

Trata-se de um segmento de extrema importância na produção de alimentos, interferindo positivamente no desenvolvimento sustentável. Como já explicitado, há uma identidade específica e diferenciada da agricultura familiar em relação à agricultura patronal, modernamente denominada de agronegócio. Aqui entram aspectos culturais, de convivência e respeito para com o ambiente e a comunidade rural, sem descuidar da importante tarefa de produção da maior parte dos alimentos que vão diariamente para a mesa do consumidor. Constitui-se, desta forma, em elemento importante na garantia da soberania alimentar, o que demonstra a necessidade e urgência em garantir a efetiva ampliação do crédito e a universalização da assistência técnica pública para este segmento importante de produtores rurais, realidade ainda muito distante para grande parte dos agricultores familiares.

Com base no exposto, a agricultura familiar não pode ser interpretada à luz da lógica capitalista, de busca de lucro, muitas vezes à custa da destruição ambiental. Há uma cultura camponesa que alia 
produção, em quantidade e qualidade, e convivência com a família, com a comunidade e com a natureza.

Assim, ampliado o conceito original de propriedade familiar e melhor definido o sentido e alcance da agricultura familiar, nas condições aqui expostas também identificadam como agricultura camponesa, com repercussões no campo das relações contratuais, no campo previdenciário e na forma de uso e convivência com a terra, faz-se necessário reconhecer formalmente a existência desta categoria específica, inclusive paras fins de organização sindical e na criação de cooperativas próprias, rompendo com os atuais limites impostos pela legislação, em consonância com a garantia de liberdade de organização sindical estabelecida pela Constituição Federal.

\title{
FAMILY PROPERTY - CONCEPTUAL EVOLUTION AND FORMAL ACKNOWLEDGMENT OF A NEW RURAL CATEGORY
}

\begin{abstract}
This study has a central focus on family property and its conceptual evolution, since the Brazilian Land Statute (Law $n^{\circ} 4504 / 1964$ ), seeking to verify the influence of the Federal Constitution in this evolution and its current contours, resulting in the identification of a specific rural community with specific interests, for which, in accordance with Law $n^{a} 11326 / 2006$, are fixed guidelines for formulating specific policies related to obtaining credit, technical assistance and marketing of production. This production is geared mainly for local and regional supply, positively interfering in sustainable rural development and in the income distribution in countryside. In the field of social security, this family farmer is identified as special insured person, since he works in a family economy regime and has, in any way, a land area of up to 04 (four) fiscal modules. However, this evolution, with the practical recognition of a new category of family farmers and rural entrepreneurs, has not been accompanied by the necessary changes in the legislation in order to formal recognize this community as a specific category also to purposes of trade union and cooperative organization .
\end{abstract}

Keywords: Family Property. Family Agriculture. Peasant Agriculture. New Rural Category.

\section{Notas explicativas}


1. Art. 147 da Constituição Federal de 1946 - Art 147 - O uso da propriedade será condicionado ao bem-estar social. A lei poderá, com observância do disposto no art. 141, § 16, promover a justa distribuição da propriedade, com igual oportunidade para todos.

2.

Disponivel

em: <http://www.planalto.gov.br/ccivil_03/Constituicao/Emendas /Emc_anterio r1988/emc05-61.htm>

3.

Disponivel

em: <http://www.planalto.gov.br/ccivil_03/leis/18629.htm>, mensagem de veto.

4.

Disponivel

em:

<http://www.planalto.gov.br/ccivil_03/decreto/D1946.htm>

5.

Disponivel

em:

<http:/ /www.planalto.gov.br/ccivil_03/decreto/2001/D3991.htm>

\section{Referências}

BARROS, Wellington Pacheco. Curso de Direito Agrário. V.1, 6. ed. Porto Alegre: Livraria do Advogado Editora, 2009.

BRASIL. Instituto Nacional de Colonização e Reforma Agrária. Procuradoria Federal Especializada. A Lei $\mathbf{8 . 6 2 9 / 9 3}$ comentada por procuradores federais. Brasília: INCRA, 2011.

CALDART, Roseli Salete, et alli (Org.). Dicionário da Educação do Campo. Rio de Janeiro, São Paulo: Escola Politécnica de Saúde Joaquim Venâncio/Fiocruz, Expressão Popular, 2012.

CARVAlHO, Edson Ferreira de. Manual Didático de Direito Agrário. Curitiba: Ed. Juruá, 2010.

CAUME, David José. A agricultura familiar no estado de Goiás. Coleção Quíron, Série Agros, v. 1. Goiânia: Editora da UFG, 1997.

MANIGLIA, Elisabete. A atividade agrária sustentável como instrumento de segurança alimentar. In: <http//WWW.reformaagraria.org/node/537>. Acessado em 12/02/2009.

MARQUES, Benedito Ferreira. Direito Agrário Brasileiro. $10^{\mathrm{a}}$ Ed. São Paulo: Ed. Atlas, 2012. 
MIGUEL NETO, Sulaiman. Questão Agrária. Campinas - SP: Bookseller, 1997.

OPITZ, Silvia C. B. e OPITZ, Oswaldo. Curso Completo de Direito Agrário. 3. Ed. São Paulo: Saraiva, 2009.

Artigo submetido para avaliação em 05 de fevereiro de 2013 e aceito para publicação em 19 de junho de 2013. 